\title{
Internal and External Environment Analysis on Financial Strategy in Chinese PV Enterprise
}

\author{
Yongchen $\mathrm{Li}^{1, \mathrm{a}}$, Fang $\mathrm{Li}^{1, \mathrm{~b}}$ \\ ${ }^{1}$ School of Economics and Management, North China Electric Power University, Baoding 071000, \\ China \\ a1510142150@qq.com, bWorkmbox_beryl@126.com
}

Keywords: PV enterprise; financial strategy; improved grey relationship analysis method; fuzzy evaluation method

\begin{abstract}
Development of Chinese PV industry meets great obstacles in current. Aiming to find out the indices prevent the development of Chinese PV enterprise and put forward constructive advices for that, this paper analyzed the internal and external environment on financial strategy of YINGLI GROUP bases on improved grey relationship analysis method and fuzzy evaluation method. The study found that indices of supports of national government policy, good development situation of new energy industry and internal self-developed technology have the greatest impact on PV enterprise. Therefore, some suggestions as follows are given by this paper, that is, finance-related policies such as subsidies, tax and financing should be fully utilized to generate profit and opportunities for enterprise when formulating financial strategies, increasing investment of fund for technology research and development within the enterprise and exploit domestic market.
\end{abstract}

\section{Introduction}

Photovoltaic (short for PV) industry refers to the chain that formed with application development of silicon material as the core, and includes production of crystalline silicon material, silicon-bonded wafer and solar cells, encapsulation of components and application of PV power generation system $^{[1]}$. In recent years, rapid development has appeared in domestic PV industry with large number of PV companies established in support of national policies, which made China become the largest PV component producers in the world in $2007^{[2]}$. However, development of PV enterprises are facing severe situation at the international and domestic still, such as intense competition in the global market, falling growth in demanding for PV products, large investment in PV R\&D technology and high cost of PV power, etc.. For this, corresponding countermeasures angle in financial strategy of enterprises were put forward that mainly include investment strategy, fund-raising strategy and dividend distribution strategy, pertinence and operability of which are inadequate mainly due to the lack of scientific analysis on internal and external environment of PV enterprises. Thus, improved grey relationship analysis method was proposed to analyze the internal and external environment on financial strategy in Chinese PV enterprise and provide references with fuzzy evaluation method combined and YINGLI GROUP of which the PV module shipments ranked first in the world as object.

\section{The Improved Grey Relationship Analysis Method and Fuzzy Evaluation Method}

\subsection{The Improved Grey Relationship Analysis Method}

The traditional grey relationship analysis is comparative analysis by quantifying dynamic development process of factors. The calculation steps are as follows ${ }^{[3]}$ : First, generate standard data array and comparative series after determining factors and collecting original data at each point in the time series. Second, generate new standard data array and comparative series after initial treatment performed in original data usually by dividing all original data with the first one in the same series. Third, calculate the correlation coefficient of comparative series at each time point respectively. Fourth, calculate the correlation degree by weighting averaging the correlation coefficients. Fifth, descending order comparative indices by correlation degree, this shows the degree of influence on standard factors. 
However, the traditional grey relationship analysis method describes the systematic development trend, that is, the original statistics are often values in time series of each index. But it's in applicable when statistics of factors are unable to get or study on time series changes is pointless. And uncertainty exists in weights due to that correlation among indices vary with the change of distinguish coefficient. Even more, qualitative method like expert evaluation should be used in case of the loss of information of original data caused by using mathematical methods simply. And this paper improved the traditional grey relationship analysis method by introducing in experts' value of empirical judgment for the weight of each factor. And the specific calculation steps are as follows [4]:

First, hire experts within the industry to select the key indices according to conditions of the external economic, social, policy, situation of industry development and enterprise itself, and to judge their weights in the system then, and thereby form an experience judgment matrix as follow.

$X=\left(x_{i k}\right)_{m n}=\left(X_{1}, X_{2}, X_{3} \ldots X_{m}\right)^{\mathrm{T}}$

Then, generate the standard data array $X_{0}$ formed by the maximum value of weights in matrix $X$.

$X_{0}=\left(x_{01}, x_{02}, x_{03} \ldots x_{0 n}\right)$

Then the distance between each comparative series and standard data array:

$$
D_{O i}=\sum_{k=1}^{n}\left(x_{O k}-x_{i k}\right)^{2}
$$

Then, the weight of each index:

$$
w_{i}=1 /\left(1+D_{0 i}\right)
$$

Finally, normalize the weight of each index in formula (4):

$$
w_{i}^{*}=w_{i} / \sum_{i=1}^{n} w_{i}
$$

\subsection{Fuzzy Evaluation Method}

Fuzzy evaluation method makes comprehensive evaluation based on the principle of maximum membership degree introduced from fuzzy mathematics, and be calculated as follows ${ }^{[5]}$ :

First of all, an evaluation team should be established of which members constituted by managers and researchers related to enterprise management practice and research to select important indices.

Then, an evaluation set V should be established, according to which each index will be evaluated. And $\mathrm{V}=$ \{good, better, general, poor, very poor $\}$. Thus, the evaluation matrix presented as follow: $R=\left(r_{i j}\right)_{m n}=\left(R_{1}, R_{2}, R_{3} \ldots R_{m}\right)^{\mathrm{T}}$

Finally, do fuzzy operations by the following formula with $w_{\mathrm{i}}^{*}$ and evaluation matrix:

$$
B=w_{i}^{*} \bullet R
$$

\section{Empirical Analysis}

\subsection{Selecting important indices}

(1) External opportunity

$\mathrm{X} 1$ : China is rich in solar energy resources. Most of Chinese vast territory possesses long hours of sunshine and high solar radiation intensity, which create great potential of solar energy exploitation.

X2: With the national policies supporting development of PV industry and the improvement of policy system, space of “compensatory growth” has given to PV industry. In July 2012, National Energy Board expressed support PV capacity of more than $21 \mathrm{GW}$ in $2015^{\text {[2] }}$ and of $50 \mathrm{GW}$ in 2020 ${ }^{[6]}$. At June 8, 2015, National Energy Board, the Ministry of Industry and Information Technology and CNCA jointly issued "Opinions on promoting the application of advanced PV technology products and industrial upgrading” to support the PV industry.

(2) External threats

X3: Operations of PV companies are attacked by the poor macroeconomic situation to some degree. 
X4: Domestic PV products occupy a very small market size which and Western countries products a gap still exist between the market acceptance for.

X5: Domestic and international market competition intensifies lead to overcapacity. Numerous homogenization of development in Chinese PV industry, the rise of the PV industry in Malaysia and Philippines and joint expansion of production capacity from two solar energy giants of First Solar and Sun Power increased competition in domestic and foreign markets.

X6: Chinese industry relied heavily on the international market, such as the substantial imports of silicon material and large exports of solar products. Foreign economic situation, policy changes and fluctuations in foreign exchange rates, etc. affect the development of Chinese PV business, and China is facing crises of "anti-dumping, anti-subsidy".

(3) The internal advantage

X7: PV industry is in line with long-term national development plan and there are good prospects by following the trend of era with increasing global warming and environmental pressures.

X8: Operating conditions improved with the expansion of industrial scale. YINGLI got a high record of PV module shipments of 3.3GM and gross margin year growth of 6.4\% percent in 2014 .

(4) The internal disadvantage

X9: Difficulties and high cost in financing caused by high business risk restricted the development.

X10: Core technology and advanced equipment mainly rely on developed countries due to the lack of R\&D. And the production of High-purity polycrystalline seriously pollutes the environment [7]

\subsection{Index System}

An index system shown as Figure 1 can be established according to the key factors above.

$\begin{gathered}\begin{array}{c}\text { External } \\
\text { external } \\
\text { environment } \\
\text { analysis on } \\
\text { financial } \\
\text { strategy in } \\
\text { PV } \\
\text { enterprise } \\
\text { environment }\end{array} \\
\text { Internal and } \\
\text { Internal }\end{gathered} \mid$\begin{tabular}{c|c|c|} 
Internal \\
strengths
\end{tabular}

Fig. 1 Index system for internal and external environment analysis on financial strategy of YINGLI GROUP

\subsection{Weighting Based on Improved Grey Relationship Analysis Method}

The empirical judgments indicators $\mathrm{X}_{1}$ to $\mathrm{X}_{10}$ of five experts are shown as in Table 1 .

Table 1 Judgment value of weights for the internal and external environmental analysis of YINGLI

\begin{tabular}{ccccccccccc}
\hline Num. & $\mathrm{X}_{1}$ & $\mathrm{X}_{2}$ & $\mathrm{X}_{3}$ & $\mathrm{X}_{4}$ & $\mathrm{X}_{5}$ & $\mathrm{X}_{6}$ & $\mathrm{X}_{7}$ & $\mathrm{X}_{8}$ & $\mathrm{X}_{9}$ & $\mathrm{X}_{10}$ \\
\hline 1 & 0.08 & 0.2 & 0.06 & 0.11 & 0.03 & 0.04 & 0.15 & 0.09 & 0.1 & 0.14 \\
2 & 0.08 & 0.22 & 0.07 & 0.08 & 0.04 & 0.03 & 0.16 & 0.09 & 0.07 & 0.16 \\
3 & 0.09 & 0.19 & 0.05 & 0.09 & 0.06 & 0.04 & 0.17 & 0.06 & 0.1 & 0.15 \\
4 & 0.07 & 0.16 & 0.1 & 0.12 & 0.05 & 0.1 & 0.14 & 0.03 & 0.13 & 0.1 \\
5 & 0.03 & 0.23 & 0.12 & 0.06 & 0.02 & 0.06 & 0.16 & 0.06 & 0.09 & 0.17 \\
\hline
\end{tabular}

Experience judgment matrix is shown as formula (8) according to Table 1 with comparative 
series $\mathrm{X}_{1}$ to $\mathrm{X}_{10}$ and the maximum weight value of 0.23 set to the weight of standard data array $\mathrm{X}_{0}$.

$$
X=\left(X_{0}, X_{1}, \cdots, X_{10}\right)^{\mathrm{T}}=\left[\begin{array}{ccccc}
0.23 & 0.23 & 0.23 & 0.23 & 0.23 \\
0.08 & 0.08 & 0.09 & 0.07 & 0.03 \\
0.20 & 0.22 & 0.19 & 0.16 & 0.23 \\
0.06 & 0.07 & 0.05 & 0.10 & 0.12 \\
0.11 & 0.08 & 0.09 & 0.12 & 0.06 \\
0.03 & 0.04 & 0.06 & 0.05 & 0.02 \\
0.04 & 0.03 & 0.04 & 0.10 & 0.06 \\
0.15 & 0.16 & 0.17 & 0.14 & 0.16 \\
0.09 & 0.09 & 0.06 & 0.03 & 0.06 \\
0.10 & 0.07 & 0.10 & 0.13 & 0.09 \\
0.14 & 0.16 & 0.15 & 0.10 & 0.17
\end{array}\right]
$$

Results are obtained as in table 1, table 2 and table3 according to formula (3) to formula (5):

Table 2 Distance between comparative series and standard data array

\begin{tabular}{ccccccccccc}
\hline DIS & $D_{01}$ & $D_{02}$ & $D_{03}$ & $D_{04}$ & $D_{05}$ & $D_{06}$ & $D_{07}$ & $D_{08}$ & $D_{09}$ & $D_{10}$ \\
\hline Val. & 0.1302 & 0.0075 & 0.1159 & 0.0975 & 0.1815 & 0.158 & 0.0279 & 0.137 & 0.089 & 0.0399 \\
\hline \multicolumn{8}{c}{ Table 3 Weights of indices $\left(w_{\mathrm{i}}\right)$} \\
\hline$w_{\mathrm{i}}$ & $w_{1}$ & $w_{2}$ & $w_{3}$ & $w_{4}$ & $w_{5}$ & $w_{6}$ & $w_{07}$ & $w_{8}$ & $w_{9}$ & $w_{10}$ \\
\hline Val. & 0.8847 & 0.9926 & 0.8961 & 0.9112 & 0.8464 & 0.8636 & 0.9729 & 0.8795 & 0.9183 & 0.9616 \\
\hline \multicolumn{8}{c}{ Table 4 Weights of indices $\left(w_{\mathrm{i}}{ }^{*}\right)$} \\
\hline$w_{\mathrm{i}}{ }^{*}$ & $w_{1}{ }^{*}$ & $w_{2}{ }^{*}$ & $w_{3}{ }^{*}$ & $w_{4}{ }^{*}$ & $w_{5}{ }^{*}$ & $w_{6}{ }^{*}$ & $w_{7}{ }^{*}$ & $w_{8}{ }^{*}$ & $w_{9}{ }^{*}$ & $w_{10}{ }^{*}$ \\
\hline Val. & 0.0969 & 0.1088 & 0.0982 & 0.0998 & 0.0927 & 0.0946 & 0.1066 & 0.0964 & 0.1006 & 0.1054 \\
\hline
\end{tabular}

\subsection{Comprehensive Evaluation Based on Fuzzy Evaluation Method}

In order to determine internal strengths and external opportunities accurately and avoid threats and weaknesses contrapuntally, it's necessary to apply fuzzy evaluation method to internal and external environment analysis following the improved grey relationship analysis method.

The fuzzy relationship matrix $\mathrm{R}$ based on evaluation set $\mathrm{V}$ is shown as formula (9).

$$
R=\left[\begin{array}{ccccc}
0.32 & 0.35 & 0.2 & 0.13 & 0 \\
0.55 & 0.44 & 0.01 & 0 & 0 \\
0 & 0.03 & 0.10 & 0.43 & 0.44 \\
0 & 0 & 0.15 & 0.41 & 0.44 \\
0 & 0 & 0.21 & 0.42 & 0.37 \\
0 & 0 & 0.11 & 0.44 & 0.45 \\
0.51 & 0.42 & 0.07 & 0 & 0 \\
0.39 & 0.35 & 0.26 & 0 & 0 \\
0 & 0 & 0.16 & 0.48 & 0.36 \\
0 & 0 & 0.05 & 0.43 & 0.52
\end{array}\right]
$$

Calculate the fuzzy evaluation matrix B according to the formula (7):

$B=w_{i}^{*} \bullet R=(0.1828,0.1632,0.129,0.27,0.255)$

\section{Conclusion}

Through analysis, we can conclude that three indices of $\mathrm{X}_{2}, \mathrm{X}_{7}$ and $\mathrm{X}_{10}$ have the greatest impact on PV enterprises. On the whole, there is not only a positive side but also a downside in the internal and external environment in Chinese PV enterprises, and following views are suggested for 
scientific financial strategies builds. Firstly, the governments are very supportive of the development of PV industry currently, and various favorable policies have been introduced which need to be studied by business managers. And ones especially related to government subsidies, tax incentives and the credit, etc. are strongly suggested when formulating financial strategies. Secondly, pay attention to introduction and cultivation of R\&D personnel of talent, improving the fund investment for technology research and trying breaking through technical difficulties and improving the quality of products in order to reduce product costs radically. Finally, international market has been expanded to some degree by PV enterprises sponsoring activities like global large-scale events for a long time. However, with the shrinking of international market demand, it's emergently necessary to attract more domestic consumers by increasing the investment of exploitation of domestic market.

\section{Reference}

[1]. Wei Yang. Research on the development strategy of Chinese PV industry [D]. Chengdu: Southwestern University of Finance and Economics, 2013. (In Chinese)

[2]. CNII. Study on market development of Chinese solar PV industry [EB/OL]. http://www.chyxx.com/industry/201502/305998.html.

[3]. Sifeng Liu, Hua Cai, Yingjie Yang, etc. Advance in grey incidence analysis modelling [J]. System Engineering Theory and Practice, 2013, (8):2043-2044.

[4]. Jie Cui, Yaoguo Dang. An improved approach for determining weights of attributes in decision making based on grey incidence [J]. Chinese Journal of Management Science, 2008, 2-3.

[5]. Ying Zhang, Yanfang Feng. FAHP Evaluation on General Quality of Undergraduate [J]. Journal of Wuhan University of Technology (Social Sciences Edition), 2007, (5):707-710.

[6]. Xinhua. Three departments issued advice to promote PV technology progress and industrial upgrading [EB/OL]. http://news.xinhuanet.com/fortune/2015-06/08/c_1115549997.html

[7]. Fei Tan. Study on Sustainable and Healthy Strategic Development of Chinese New Energy Industry [J]. Prices Monthly, 2015, (6):73-77 